\title{
POLÍTICAS PÚBLICAS E O SETOR INDUSTRIAL DE CAMPINA GRANDE - PB*
}

\section{Maria Lacia Goncalves de Carvalho Gelfa de Maria Costa Aguiar Leiliam Cruz Dantas"*}

Este artigo tem como objetivo apresentar o perfil do setor industrial de Campina Grande em 1992 a partir das modificações ocorridas na década de 60 , em função da criação da SUDENE. Ao longo do estudo foi possível detectar a importância deste órgão, através de suas ações, na redefinição da estrutura do setor secundário deste município.

$\Lambda$ evolução do referido setor foi observada comparando três momentos distintos: o período anterior à criação da SUDENE; o posterior à sua criação até o ano de 1979 e, finalmente, o compreendido entre 1980 a 1992.

O estudo tomou como base os levantamentos realizados pela Federação das Indústrias do Estado da Parába - FIEP nos anos 1969,1979 e 1992, considerando as seguintes variáveis: número de empresas nos vários ramos produtivos e a mão-de-obra empregada.

$$
* * *
$$

Inicialmente, as acões da SUDENE para o Nordeste, visaram soerguer as indústrias tradicionais ${ }^{40}$ - como a de couros,

\footnotetext{
"Este artigo é parte de uma pesquisa sobre o Sefor Industrial de Campina Grande, realizada entro maio e agosto de 1995.

${ }^{\star *}$ Professoras do Departamento de Econonia e Finanças da Universidade Federal da Paraiba, CAMPUS $\Pi$.

40 Conforme o IBGE, as indústrias tradicionais são: Madeira, Mobiliátio, Couros e Peles, Têxtil, Vestuário, Produtos Alimentares, Bebidas, Fumo, Editorial e Gráfica e Diversas.
} 
óleos vegetais e especialmente a têxtil-algodoeira - além de fomentar indústrias dinâmicas ${ }^{41}$, que aproveitassem a matéria prima local e apresentassem possibilidades de competir, tais como A exemplo das indústrias de cimento, adubos, fosfatados, entre outros.

Pesquisas realizadas pela SUDENE, nos seus primeiros anos de atuação, constataram que as indústrias tradicionais acima indicadas apresentavam obsoletismo, em termos de equipamentos, técnicas de produção e gestão administrativa, o que suscitou ações no sentido de reequipar as empresas existentes e implantar novas unidades ${ }^{42}$. Como resultado destas açoes, observouse a ampliação da capacidade produtiva tanto no setor têxtil quanto no setor coureiro, como também medidas que visavam a qualificação da mão-de-obra. Nesta perspectiva, foi implantado, em Recife, o Centro de Treinamento Têxtil do Nordeste, com apoio do governo japonês, e em Campina Grande, o Programa Regional de Pesquisas e Processamento em Couros e Tanantes, com apoio da UFPB.

No âmbito do Programa relativo ao ramo coureiro, ressaltase a criação do PROCUR' (Centro de Tecnologia de Couros e Tanantes) da UFPB, que atualmente, funciona como suporte ao Centro de Tecnologia do Couro Albano Franco (CTCC), criado em novembro de 1994.

Em uma segunda etapa, a partir de 1970, ações se destinaram ao desenvolvimento, na região, de empresas capazes de modificar o perfil da estrutura industrial, com ênfase para aquelas consideradas dinâmicas. Para tanto, o instrumento 34/18 transformado em FINOR (Fundo de Investimento do Nordeste) a

41 Do acordo com o $\mathrm{BBGE}$ as indústrias dinâmicas são: Produtos Murerais Não-Motálicos, Metalúrgica, Mecânica, Materiais Elétricos e Eletrônicos, Material de Transporte, Papel e Papelão, Borracha, Quimica, Produtos Famacêtucos e Veterinários, Perfumaria, Sabão o Velas e Produtos de Matérias Plásticas.

42 Resulton deste programa a ampliação do número de fusos na indústria têxtíl, passando de 642.300 em 1960 para 1.310 .800 em 1978 e ampliaçăo da capacidade de curtimento para 2,97 milhôes de couros/ano e 8,23 wilhöes de peles/ano, mostrando um crescimento de 134 e $180 \%$, respectivamente, em relação ao ano de 1970, de acordo com o documento SUDENE VINTE ANOS, 1979. 
partir de 1974, administrado pela SUDENE e operacionalizado pelo BNB - promove, a partir da implantação de um núcleo siderúrgico, o desenvolvimento de empresas tanto nacionais quanto estrangeiras. Isto se configurou como base para a posterior expansão dos ramos de produção Mecânico e Metalúrgico, responsável pela transformação do parque industrial nordestino, cujas empresas caracterizam-se por maior grau de modernidade e competitividade.

No mesmo período destacam-se alguns segmentos dinâmicos, cujos índices anuais de crescimento apresentam-se bastante positivos, como: Metalúrgica (23,3\%), Mecânica (35,8\%), Materiais Elétricos e Eletrônicos $(37,6 \%)$ e Produtos de Matérias Plásticas $(49,1 \%)^{43}$. Neste sentido, as repercussōes dessas ações tornam-se evidentes com a diminuição das indústrias tradicionais no Nordeste que, em 1960, respondiam por $70 \%$ no valor da transformação industrial, reduzindo sua participação para 50\% em 1974.

Cabe ainda ressaltar que as modificacões estruturais ocorridas, beneficiaram notadamente as indústrias Metalúrgica e Quimica. Neste contexto, ocorre a implantação do Complexo Petroquímico do Nordeste, localizado em Camacari no estado da Bahia, responsável por cerca de $50,0 \%$ da capacidade nacional de produtos petroquímicos, álcalis cáusticos e cloro. Em paralelo inicia-se a produção de fertilizantes e de barrilha.

Além destes segmentos, a SUDENE desenvolveu pesquisas acerca das pequenas e médias empresas do Nordeste e concluiu que estas eram significativamente importantes, em termos de absorção de mão-de-obra e geração do produto interno. No entanto, as mesmas não apresentayam os requisitos necessários para receber os incentivos do FINOR e por isto a SUDENE implementou outros mecanismos de apoio a exemplo do Programa de Assistência Técnica e Financeira às Pequenas e Médias Fmpresas Industriais do Nordeste, primeira experiência a nível nacional. $O$ referido Programa, coordenado pela SUDENE em parceria com 0

${ }^{43}$ Fonte: IBGE - Censo Industrial 1960 e Pesquisa Industrial 1974 apud MINTER. SUDENE VINTE ANOS. Recife, 1979. p.97. 
BNB e o CEBRAE (Centro Brasileiro de Apoio à Pequena e Média Empresa), fundamentava-se no treinamento de empresários, assistência financeira e serviços de pesquisa e extensão. ${ }^{4}$

Atualmente, o SEBRAE ${ }^{45}$ (Serviço Brasileiro de Apoio à Pequena e Média Empresa), continua apoiando o crescimento e desenvolvimento das micro e pequenas empresas ${ }^{46}$, a partir de tratamento diferenciado ${ }^{47}$, por reconhecer que elas são um elemento dinamizador no desenvolvimento econômico da região.

\section{$* * *$}

Campina Grande, ao contrário do constatado na região Nordeste, apresenta, em 1992, índices de crescimento bastante relevantes para os ramos Vestuário e Calçados, e desempenho pouco significativo, para os ramos Metalúrgica e Minerais NãoMetálicos, no que se refere ao número de empresas.

Nos anos anteriores à criação da SUDENE, é possível identificar que as indústrias tradicionais eram predominantes na estrutura industrial de Campina Grande. Entre os ramos mais representativos neste período, destacavam-se os seguintes: Indústria de Produtos Alimentares com 14 empresas, Indústria Extrativa de Produtos Vegetais com 08, Indústria de Couros, Peles e Produtos Similares com 06 e Indústria Têxtil com 05. Convém destacar ainda a presença de apenas 01 (um) ramo considerado dinâmico, a Indústria Metalúrgica, com 06 empresas ${ }^{48}$.

44 MINTER. SUDENE VINTE ANOS. Recife, 1979.

45 Segundo informações obtidas junto ao SEBRAE - Campina Grande, a mudança de sigfa, resultou do uma padronização realizada a ni vel estadual, no inicio dos anos 90 .

46 Do acordo com o Projeto de Lei $1^{\circ} 3081-\mathrm{E}$, de 1989, são consideradas micro-empresas $\theta$ empresas de pequeno porte aquelas que obtêm renda bruta anual igual ou inferior a 250.000 e 700.000 UFIR (Unidades Fiscais de Referência), respectivamente.

${ }^{47}$ As micro e pequenas empresas, conforme Projeto de 1989 , devem receber tratamento diferenciado nos campos administrativo, fiscal, previdenciário, trabalhista, de desenvolvimento empresarial e creditício, sendo-lhes facultadas condições favoráveis de funcionamento.

48 Dados retirados do Cadastro Industrial do Estado da Paraíba - 1969. Considerou-se apenas os ramos om que foram criadas cinco ou mais empresas. 
Vimos que antes de 1960 só existia 33 empresas do segmento tradicional, o qual registra um crescimento, chegando a atingir $113 \mathrm{em} \mathrm{1969,} \mathrm{o} \mathrm{que} \mathrm{reflete} \mathrm{as} \mathrm{ações} \mathrm{implementadas} \mathrm{pela}$ SUDENE, na perspectiva de soerguer a indústria existente na Região. Neste sentido, destacam-se os ramos de Produtos Alimentares, com acréscimo de $91 \%$, seguido da Indústria de Couros e Peles, com $50 \%$ e a Têxtil com $44 \%$. Cabe ainda ressaltar que o ramo de produção Indústria Extrativa Vegetal, que beneficiava o algodão e o sisal, foi totalmente absorvido pelo ramo Indústria Têxtil. Atente-se ainda para o crescimento verificado nos ramos antes não representativos como: Editorial e Gráfica (93\%), Vestuário e Artefatos de Tecido (98\%), Calçados (96\%), Madeira (97\%), Mobiliário (94\%) e Bebidas (80\%).

O mesmo comportamento estendeu-se aos anos 70, uma vez que manteve-se a predominância do segmento tradicional sobre o dinâmico, conforme indicam os dados seguintes: em 1969, as indústrias tradicionais representavam $32,7 \%$ (113 de 348) do total das existentes e em 1979 passou para 59,2\% (224 de 382).

Neste período, constata-se também a existência de indústrias dinâmicas, com destaque para os ramos Minerais NãoMetálicos e Metalúrgica.

No período compreendido entre 1980-92, os ramos entendidos como dinâmicos apresentam um relativo crescimento, registrando o surgimento de 146 empresas, das 186 existentes em 1992. Das empresas surgidas neste periodo, destaca-se a Indústria Metalúrgica com 69 empresas e a Indústria de Minerais NãoMetálicos, com 45.

A Metalúrgica caracteriza-se pela presença de um pequeno número de grandes empresas, que absorvem a maior parte da mão-de-obra empregada no ramo. Dos 888 operários registrados neste ramo em $1992,61,0 \%$ são vinculados a apenas 05 empresas $^{49}$, ficando os demais (39\%) distribuídos em 86 empresas.

\footnotetext{
49 Compaço Engenharia Estruturas Metálicas Ltda., fundada eln 1986, com 88 operários; TMAI, fundada em 1974, empregando 66 operários; MONTAL, fuudada em 1976, com 90 operários; Metalouça, fundada om 1970, com 139 operários e Silvana, fundada em 1961, com
} 
O ramo de Minerais Não-Metálicos também merece ser ressaltado, pois passa de 24 empresas em 1979 para 53 em 1992 . A característica deste ramo assemelha-se ao do anteriormente mencionado, concentrando aproximadamente $50 \%$ da mão-de-obra em apenas 03 empresas ${ }^{50}$ e distribuindo o restante dos operários nas outras 50 empresas.

Ainda em relação ao segmento dinâmico, é importante registrar o crescimento dos ramos Material Elétrico, Eletrônico e de Comunicação, com o surgimento de 06 empresas no periodo em foco (1980-92), Indústria de Produtos de Matérias Plásticas e Indústria Química, com 15 e 11, respectivamente.

Neste período, o segmento tradicional mantém sua predominância em relação ao dinâmico, com 581 empresas das 805 existentes em $1992(72,2 \%)$.

Outro aspecto que deve ser ressaltado ao analisar o segmento tradicional diz respeito à presença de empresas de pequeno porte, uma vez que nesta fase identificam-se ações no sentido de apoiar e financiar a sua implantação efetivadas, sobretudo, pelo SEBRAE, além de outros agentes de fomento. Isto torna-se patente no fato de que dentre os oito ramos de produção destacados como os mais representativos em 1992, quatro deles - Indústria de Produtos Alimentares, Calçados, Vestuário e Mobiliário - absorvem entre 01 e 10 operários, em média ${ }^{\text {st }}$, em mais de $80 \%$ de suas empresas.

Levantamentos realizados em 1994 pela Secretaria da Indústria, Comércio, Turismo, Ciência e Tecnologia - PB, no segmento Coureiro Calçadista (que compreende Indústria de Couros, Peles e Similares e Indústria de Calçados) verifica que ao lado do. setor formal, ocorre um expressivo aumento no número de empresas informais neste ramo produtivo, sendo que das 317 empresas

160 operários.

${ }^{50}$ PREMOL, fundada em 1959, com 68 operários; BUंN, fundada em 1965 e filial em 1982, com 81 operários; Dolomil Dolomita Minérios Ltda., fundada em I975, com 123 operánios.

${ }^{51}$ Indústria de Produtos Alimentares (86\% das empresas empregam entre 01 e 10 operários); Calçados (70\%); Vestuário (85\%) • Mobiliánio (94\%). 
existentes no Estado, 186, ou seja, (58,7\%), situam-se em Campina Grande e empregam $59,9 \%$ dos operários ${ }^{52}$. A respeito do setor formal deste segmento, constata-se que não houve modificação com referência a $1992^{53}$, pois os dados mostram que das 85 empresas da Paraíba, 51 localizam-se em Campina Grande, as quais empregam 2.927 operários, ou seja, 48,4\% do total empregado na Paraíba (6.053).

A partir do exposto evidencia-se um perfil, com a presenca de ramos de produção tanto dinâmicos como tradicionais, sendo que este último segmento mostra-se mais significativo, ressaltando-se em seu contexto a existência de um considerável número de microempresas notadamente na Indústria de Calçados e na Indústria de Vestuário.

Verifica-se também que a indústria de Campina Grande registrou um crescimento em torno de $66 \%$ entre 1960 e 1979, porém, o grande boom, em termos de surgimento de novas empresas industriais, ocorreu no período de 1980 a 1992, com uma elevação de $82 \%$, refletindo portanto a segunda fase de ação da SUDENE.

Em termos gexais, pode-se constatar que houve um crescimento bastante significativo no número de empresas, uma vez que as mesmas passaram de 348 em 1969, para $805 \mathrm{em} 1992$, representando portanto uma expansão de $131,3 \%$. O setor industrial de Campina Grande aumentou sua participação no total das empresas do estado da Paraíba, embora em pequena proporçāo: em 1969, era de $19,2 \%$ (348 em 1.810) e em 1992, passou para $23,9 \%$ (805 em 3.340).

$$
* \star *
$$

f possivel concluir que Campina Grande apresenta, em

\footnotetext{
52 Em termos absolutos isto significa 1.108 operánios em um total de 1.849 na Paraíba. Fonte: ESTADO DA PARAÍBA. Secretaria da Indústria, Comércio, Turismo, Ciência e Tecnologia. 1994. Pesquisa Direta.

53 Em 1992 o cadastro já registrava 44 empresas no ramo de Calçados e 08 em Couros e Peles, perfazendo o total de 52 .
} 
1992, um perfil industrial caracterizado por segmentos dinâmicos e sobretudo tradicionais, não guardando portanto muitas semelhanças com o existente antes da SUDENE.

Naquela época, a tônica era dada pelos ramos tradicionais, com destaque para a Indústria Extrativa Vegetal ${ }^{54}$, a Indústria Têxtil $^{55}$ e a de Couros e Peles e Similares ${ }^{56}$, as quais perderam sua importância, nos primeiros anos da década de 90, cedendo lugar a outros ramos tradicionais como o de Calçados e o de Vestuário. É importante ressaltar que naquele período as empresas eram de grande porte e absorviam muita mão-de-obra. Em 1992, observase uma tendência inversa: a predominância de um significativo número de pequenas e médias empresas pouco absorvedoras de mão-de-obra.

Mantém-se, em 1992, como substancialmente representativo o ramo Indústria de Produtos Alimentares, cujo destaque fica para a linha de produção ligada à Panificação, fato possivelmente relacionado com o estímulo às pequenas e médias empresas industriais, ocorrido através de órgãos de fomento tipo SEBRAE. Aliese a este fator o crescimento populacional ocorrido durante o período em estudo.

Quanto ao segmento dinâmico, observa-se que antes da SUDENE, merecia destaque apenas a Metalúrgica, com 26 empresas. Em 1992, este segmento conta com mais 04 ramos, representativos em termos de criação de empresas, como Minerais NãoMetálicos; Material Elétrico, Eletrônico e de Comunicação; Produtos de Matérias Plásticas e Química. No entanto, a Metalúrgica

\footnotetext{
54 As empresas mais representativas deste ramo na linha de prodıção Beneficiamento do Algodão como SANBRA (fundada em 1936), Araújo Rique (1937), Antonio Beitino (1940), Pedro Ribeiro (1946) e a de Beneficiamento de Sisal como Pedro Sabino (1940), foram todas desativadas.

${ }^{55}$ Dentre as empresas mais significativas do ramo tem-se a permanência até os dias do hoje da Indústria Têxtil de Campina Grande (fundada em 1933) • a Cotonificio Campixense (1949) atual Campina Grande Indústrias Gerais - o mesmo não ocorrendo com Marques de Almeida (findada em 1937 o desativada nos primeiros anos da década de 1980).

${ }^{56}$ Os curtumes eram os empreendimentos mais importantes do ramo, dos quais destacavam-se Motta Irmãos (fundado em 1926) e Antonio Villarim (1936), 'sendo o primeiro desativado no primeiro lustro dos anos 80 e segundo no de 90 .
} 
mantém sua jmportância (91 empresas), seguida da Indústria de Minerais Não-Metálicos, com 53 . E importante ressaltar que as grandes empresas ligadas aos ramos supracitados receberam incentivos da SUDENE.

E possivel perceber uma nova tendência no que se refere aos programas de incentivo ao setor industrial, com ênfase náa área de capacitação de recursos humanos, com vistas a viabilizar o desenvolvimento de novas tecnologias.

Dentre as experiências mais relevantes, ressalta-se a implantação da Fundação Parque Tecnológico da Paraíba (Paq'lcPB), em 1984 e do Centro de Tecnologia do Couro e do Calcado (CTCC-CG), implantado pelo Servico Nacional da Indústria (SENAI) em 1994, os quais dão suporte, em termos de treinamen. to, pesquisa e serviços de extrnsão, aos pólos coureiro/calçadista e aos de base tecnológica, notadamente na área de informática.

Com referência ao PaqTc-PB, a ênfase é dada ao programa de incubação de empresas de base tecnológica, criado em 1989, que congrega atualmente 14 empresas no sistema, estando 11 desenvolvendo software. Dentre estas destaca-se a Light Infocon, a maior de software para Unix do país, cujos produtos são comercializados no exterior e a Humana, especializada na produção de software em Oracle (hanco de dados).

Finalizando, constata-se que as aluais possibilidades, no que se refere as novas modalidades de incontivos, são apoiadas por programas de desenvolvimento de novas tecnologias, na área de treinamento e pesquisa, por iniciativa do setor privado e do setor público, no qual salienta-se a presença marcante da Universidade Federal da Paraíba. 